(A) Check for updates

Cite this: Nanoscale, 2021, 13, 3967

Received 11th January 2021,

Accepted 6th February 2021

DOI: $10.1039 / \mathrm{d} 1 \mathrm{nr} 00172 \mathrm{~h}$

rsc.li/nanoscale

\section{Dual-functional ionic porous organic framework for palladium scavenging and heterogeneous catalysis $\uparrow$}

\author{
Shun-Shun Qin, ${ }^{a}$ Ze-Kun Wang, ${ }^{a}$ Lei Hu, ${ }^{a}$ Xing-Hao Du, ${ }^{a}$ Zheng Wu, \\ Maria Strømme, (D) ${ }^{\text {b }}$ Qian-Feng Zhang ${ }^{a}$ and Chao Xu (D)*a,b
}

\begin{abstract}
Porous organic frameworks (POFs) with predesigned structures and tunable porosities have been widely studied in adsorption and heterogeneous catalysis. Introducing ionic structure into the framework endows POFs with new functionalities that may extend their applications. Here, we report new applications for a guanidinium-based ionic POF (IPOF-Cl) in palladium scavenging and heterogeneous catalysis. Due to the ionic framework and the porous structure, the IPOF-Cl displays fast adsorption kinetics and high adsorption capacities (up to $754 \mathrm{mg} \mathrm{g}^{-1}$ ) of $\mathrm{Na}_{2} \mathrm{PdCl}_{4}$ in aqueous solutions via a chemisorption (ion exchange) process. Significantly, it shows excellent scavenging activity towards trace amount of $\left[\mathrm{PdCl}_{4}\right]^{2-}$ in aqueous solution. More importantly, the loaded $\left[\mathrm{PdCl}_{4}\right]^{2-}$ species on the IPOF substrate are further reduced into ultrafine Pd nanoparticles with size of $\sim 2-5 \mathrm{~nm}$. The obtained IPOF-Pd(0) nanocomposite containing uniformly distributed Pd nanoparticles and hierarchical porous structure demonstrates high activity in catalyzing a range of Suzuki coupling reactions. This study provides new routes for the development of ionic porous organic materials for applications in metal scavenging and catalysis.
\end{abstract}

\section{Introduction}

Porous organic frameworks (POFs) are an emerging class of porous materials demonstrating unique characteristics of large specific surface areas, tunable porosities, and high physical and chemical stability. ${ }^{1-5}$ They are constructed by joining pure organic monomers via covalent bonds. From a synthetic point of view, numerous organic monomers and several organic reactions (e.g., condensation reactions, coupling reactions) can be

\footnotetext{
${ }^{a}$ Institute of Molecular Engineering and Applied Chemistry, Anhui University of Technology, Ma'anshan, 243002, P. R. China

${ }^{b}$ Department of Materials Science and Engineering, Uppsala University, The Angström Laboratory, Box 35, 75103 Uppsala, Sweden.

E-mail: chao.xu@angstrom.uu.se, chao.xu0203@outlook.com

$\dagger$ Electronic supplementary information (ESI) available. See DOI: 10.1039/ d1nr00172h
}

applied in the synthesis of POFs. ${ }^{6,7}$ By judicious selection of the monomers and the reactions, various POFs with different building blocks and architectures have been successfully synthesized. ${ }^{8-12}$ In addition, the rich organic groups in POFs enable facile modification on the surface, offering an opportunity for the functionalization of POFs. ${ }^{13}$ In this context, the synthetic diversity and the principles of reticular chemistry allow the construction of novel POFs with predesigned structures and tailored properties for various applications. ${ }^{14-21}$

Recently, a few examples of POFs consisting of ionic frameworks and counter-ions have been reported. ${ }^{22-26}$ Although the ionic POFs (IPOFs) usually have moderate surface areas due to the pore-blocking effect by the counter-ions, they demonstrate several unique advantages compared to their neutral analogs. ${ }^{27}$ For example, the ionic structure of IPOFs enables ion exchange which allows the pore size to be finely controlled by adjusting the size of counter-ions. ${ }^{28}$ Such IPOFs with controlled pore sizes demonstrated promising applications in size-selective adsorption and catalysis. ${ }^{25}$ In addition, the ionic interface in IPOFs triggers electrostatic interactions with guest molecules or ions that could enhance their performances in $\mathrm{CO}_{2}$ capture and in trapping ionic pollutants. ${ }^{26,29-32}$ Therefore, the design of IPOFs with tunable nanostructures, compositions and properties could further extend their applications in adsorption and catalysis.

Palladium catalysts (e.g., inorganic palladium salts, organopalladium, palladium nanoparticles) are widely used in a range of important organic transformations such as C-C coupling, hydrogenation, dehydrogenation. ${ }^{33}$ However, traditional homogeneous palladium catalysts usually suffer from significant recovery problems, which not only cause a waste of precious metal resource but also lead to heavy metal contamination in the products. In order to overcome these problems, it is highly desirable to develop efficient palladium scavengers and heterogeneous palladium catalysts. ${ }^{34-40}$ Given the ionic and porous structure, we envisioned that IPOFs may find applications in scavenging ionic palladium residues from solution via ion exchange and/or physical adsorption. In addition, 
immobilizing the palladium species in the porous channels of IPOFs offers a new route for the development of heterogeneous catalyst. Herein, we synthesize a dual functional IPOF-Cl composed of cationic guanidinium-based framework and chloride ions as charge-balance ions. The IPOF shows high adsorption uptake of tetrachloropalladate ions $\left(\left[\mathrm{PdCl}_{4}\right]^{2-}\right)$ in aqueous solutions. In addition, the adsorbed $\left[\mathrm{PdCl}_{4}\right]^{2-}$ ions in the porous channels are further reduced into ultrafine Pd nanoparticles (Scheme 1). As a result, the Pd nanoparticles immobilized IPOF shows high efficiency for catalytic conversion of a range of Suzuki coupling reactions.

\section{Results and discussion}

IPOF-Cl was synthesized by the condensation reaction of triaminoguanidinium chloride (TGCl) ${ }^{24}$ with 1,3,5-triformylphloroglucinol (TFP, Shanghai Tensus Bio-tech) (Scheme S1†). TGCl is a hydrochloride salt of triaminoguanidine that contains three primary amine groups, one protonated tertiary amine and one counter-ion $\mathrm{Cl}^{-}$. The rich chemistry and the high reactivity of the amine groups make TGCl an ideal ionic monomer for the synthesis of IPOFs. The structure of IPOF-Cl was studied by infrared (IR), solid-state ${ }^{13} \mathrm{C}$ nuclear magnetic resonance (NMR) spectroscopy, and powder X-ray diffraction (XRD). The strong bands at $1617 \mathrm{~cm}^{-1}$ and $1292 \mathrm{~cm}^{-1}$ displayed in the IR spectrum can be assigned to $\mathrm{C}=\mathrm{C}$ and $\mathrm{C}-\mathrm{N}$ stretching, respectively (Fig. $1 \mathrm{a}$ and $\mathrm{S} 1 \dagger$ ). ${ }^{41}$ The sharp peaks at 101 and 146 ppm observed in the ${ }^{13} \mathrm{C}$ NMR spectrum can be attributed to the exocyclic $\mathrm{C}=\mathrm{C}$ carbons. ${ }^{19}$ The chemical shifts for carbons of guanidinium $(\mathrm{C}=\mathrm{N})$ and keto $(\mathrm{C}=\mathrm{O})$ are observed at 164 and 179 ppm, respectively. ${ }^{24}$ The peak detected at $192 \mathrm{ppm}$ indicates the presence of unreacted aldehyde groups from the TFP monomer due to the reversible Schiff-base condensation reaction (Fig. 1b). Such unreacted aldehyde groups were also observed in various imine-linked porous organic polymers. ${ }^{42-44}$ The broad diffraction peaks observed for IPOF-Cl indicate relatively low crystallinity of the material compared with typical covalent organic frameworks. $^{1,8}$ The diffraction peak at $2 \theta=\sim 10.0$ can tenta- tively be assigned to the 100 reflection. The intensive peak at $2 \theta=\sim 26.8^{\circ}$ suggests the existence of $\pi-\pi$ stacking between the 2D layers in IPOF-Cl (Fig. 1c and S2 $\dagger$ ). The low crystallinity of IPOF-Cl could be explained by the fact that the repulsive interactions between the cationic layers hampered the formation of a highly ordered and closely stacked structure. In addition, $\mathrm{N}_{2}$ sorption measurements reveal that IPOF-Cl has a moderate surface area of $163 \mathrm{~m}^{2} \mathrm{~g}^{-1}$, which is lower than for many reported porous organic materials probably because the $\mathrm{Cl}$ ions partially block the porous channels. The significant adsorption uptake at high relative pressures and the existence of adsorption/desorption hysteresis suggest the formation of mesopores in IPOF-Cl. Pore size distribution analysis based on the adsorption isotherm indicates that IPOF-Cl contains micropores centered at $1.5 \mathrm{~nm}$ and mesopores with a broad distribution centered at $\sim 30 \mathrm{~nm}$ (Fig. 1d). These results are in agreement with those of reported results, ${ }^{17,24}$ which signifies the formation of guanidinium- and ketoenamine-linked IPOF-Cl with hierarchical porous structure.

As displayed in various ionic porous materials (e.g. zeolites, ${ }^{45}$ ionic porous organic polymers, ${ }^{46}$ ionic metal-organic frameworks ${ }^{47}$ ), the ionic structure could endow IPOF-Cl with ion exchange ability that can potentially be used as a scavenger for anionic metal complexes. In this context, we studied the capture capability of IPOF-Cl towards $\left[\mathrm{PdCl}_{4}\right]^{2-}$, a widely used homogeneous catalyst in a range of organic reactions. ${ }^{48,49}$ Firstly, we studied the kinetic of $\left[\mathrm{PdCl}_{4}\right]^{2-}$ capture from an aqueous solution by using IPOF-Cl. Specifically, an aqueous solution of $\mathrm{Na}_{2} \mathrm{PdCl}_{4}\left(33 \mathrm{~mL}, 0.6 \mathrm{mg} \mathrm{mL}{ }^{-1}\right)$ was mixed and stirred with grinded IPOF-Cl (20 mg) at room temperature. The $\mathrm{Pd}$ content in the solution at different intervals was determined by Inductively Coupled Plasma-Atomic Emission Spectrometer (ICP-AES). Obviously, the concentration of $\mathrm{Na}_{2} \mathrm{PdCl}_{4}$ in the solution decreased rapidly and more than $75 \%$ of the uptake was reached within the initial $10 \mathrm{~min}$. The capture kinetic curve fits well with the pseudo-second-order kinetic model, indicating that the capture process was dominated by an ion exchange (or chemisorption) process (Fig. 2a and $\mathrm{S} 3 \dagger) .{ }^{50}$ In addition, the adsorption isotherm was recorded to study the effect of $\mathrm{Na}_{2} \mathrm{PdCl}_{4}$ concentration on the capture
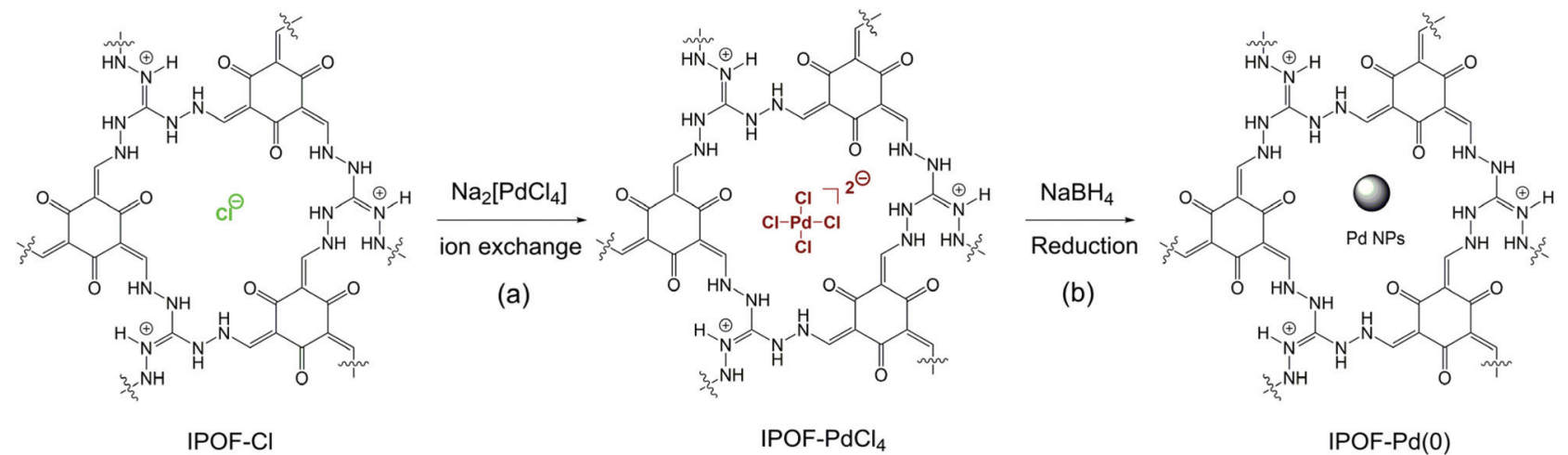

Scheme 1 (a) Schematic reaction of ion exchange of IPOF-Cl with $\mathrm{Na}_{2} \mathrm{PdCl}_{4}$; (b) reduction of IPOF-PdCl by $\mathrm{NaBH}_{4}$ into IPOF-Pd(0). 
(a)

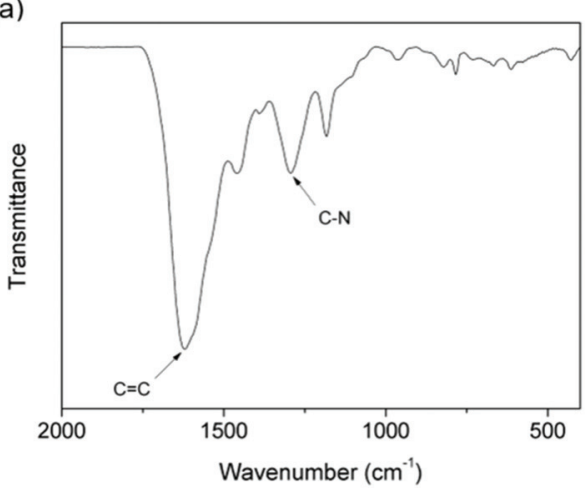

(c)

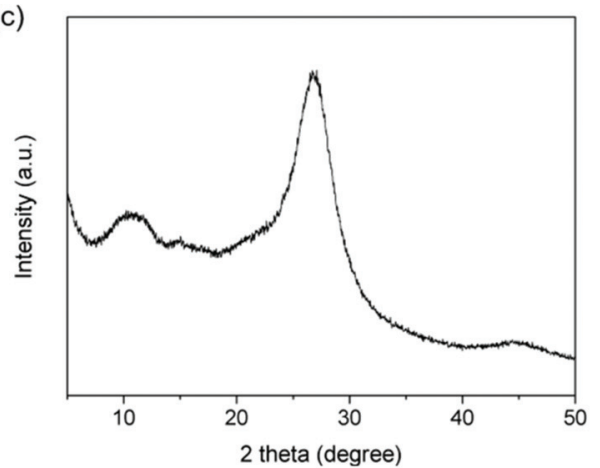

(b)



(d)

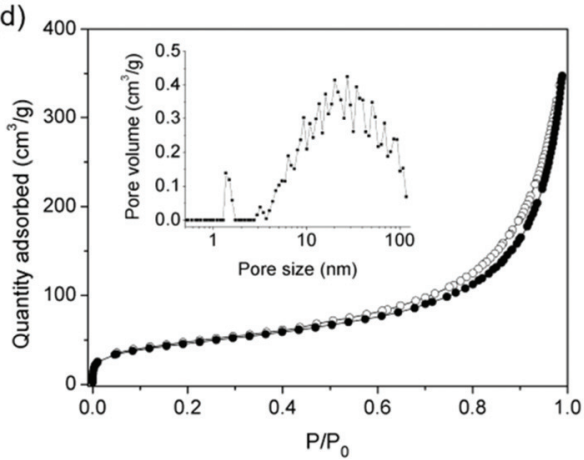

Fig. 1 (a) Infrared spectrum, (b) solid state ${ }^{13} \mathrm{C}$ nuclear magnetic resonance spectrum, (c) powder X-ray diffraction pattern of IPOF-Cl; (d) $\mathrm{N}_{2}$ adsorption and desorption isotherms of IPOF-Cl recorded at $77 \mathrm{~K}$. The inset shows the pore size distribution of IPOF-Cl calculated from the adsorption branch using density functional theory model.

(a)

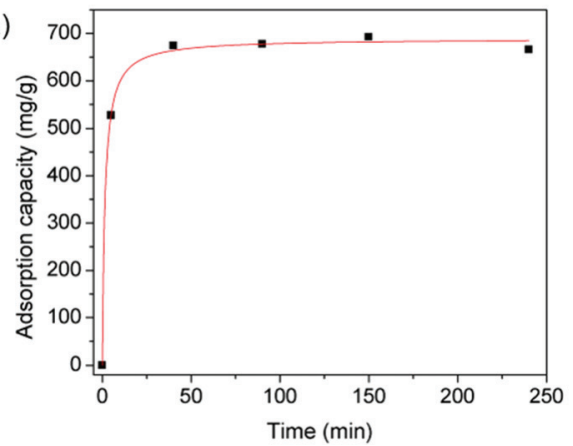

(c)

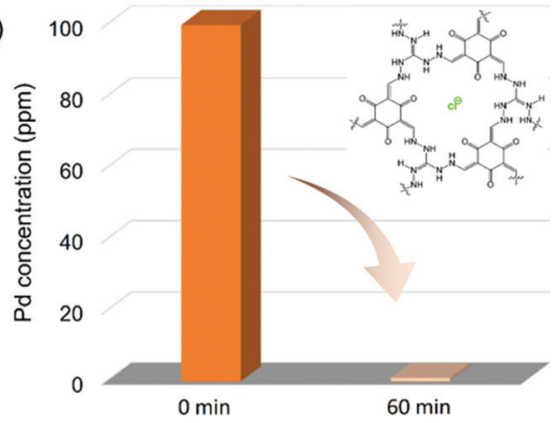

(b)

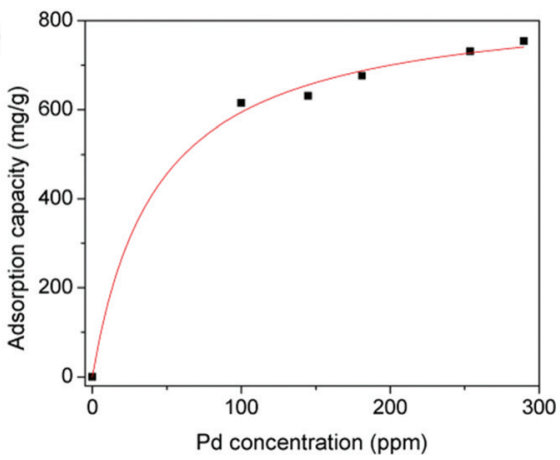

(d)

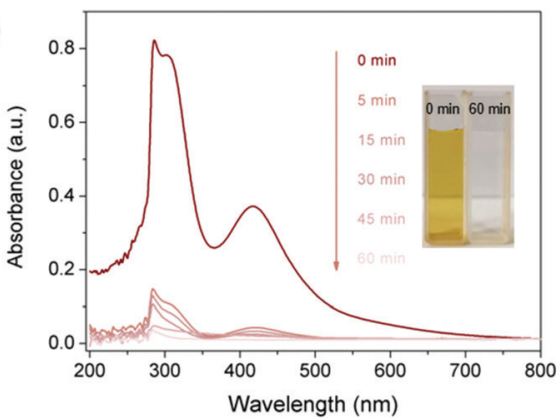

Fig. 2 (a) Kinetic curve of $\mathrm{Na}_{2} \mathrm{PdCl}_{4}$ capture on IPOF-Cl; (b) $\mathrm{Na}_{2} \mathrm{PdCl}_{4}$ adsorption isotherm of IPOF; (c) scavenging performance of IPOF-Cl towards $\mathrm{Na}_{2} \mathrm{PdCl}_{4}$ in an aqueous solution; (d) UV-vis spectra of aqueous solution of $\mathrm{Na}_{2} \mathrm{PdCl}_{4}$ at different intervals during the scavenging experiment. The inset shows the optical image of the solution before and the after the scavenging experiment. The initial concentration of the solution was 100 ppm. 
process. As shown in Fig. $2 \mathrm{c}$ and $\mathrm{S} 4, \uparrow$ the adsorption isotherm fits well with the Langmuir adsorption model. The maximum capture capacity is calculated to be $852 \mathrm{mg} \mathrm{g}^{-1}$. The value is much higher than the theoretical capacity of $572 \mathrm{mg} \mathrm{g}^{-1}$ based on ion exchange, which can be attributed to a synergetic effect of ion exchange and physisorption of $\mathrm{Na}_{2} \mathrm{PdCl}_{4}$ in the IPOF. When it reached adsorption equilibration in the aqueous solution of $\mathrm{Na}_{2} \mathrm{PdCl}_{4}\left(0.8 \mathrm{mg} \mathrm{mL}{ }^{-1}\right)$, the adsorbent was collected and its porosity was characterized by $\mathrm{N}_{2}$ sorption measurement (Fig. S5 $†$ ). Since $\left[\mathrm{PdCl}_{4}\right]^{2-}$ ions possess a larger molecular weight and size than the original counter-ions of $\mathrm{Cl}^{-}$, the replacement of $\mathrm{Cl}^{-}$with $\left[\mathrm{PdCl}_{4}\right]^{2-}$ in IPOF-Cl not only increases the bulk density and but also partially blocks the pores of the material. As a result, the surface area and the total pore volume of the sorbent are significantly reduced from
$163 \mathrm{~m}^{2} \mathrm{~g}^{-1}$ and $0.352 \mathrm{~cm}^{3} \mathrm{~g}^{-1}$ for IPOF-Cl to $48 \mathrm{~m}^{2} \mathrm{~g}^{-1}$ and $0.109 \mathrm{~cm}^{3} \mathrm{~g}^{-1}$ for IPOF-PdCl 4 , respectively. The reduced porosity also demonstrates the efficient capturing ability of IPOF-Cl towards $\left[\mathrm{PdCl}_{4}\right]^{2-}$.

Given the high uptake and the fast kinetic of the capture process, we anticipated that it can be used as an efficient scavenger for removing trace amount of $\mathrm{Na}_{2} \mathrm{PdCl}_{4}$ from aqueous solutions. Remarkably, the use of $10 \mathrm{mg}$ of IPOF-Cl reduced the concentration of aqueous $\mathrm{Na}_{2} \mathrm{PdCl}_{4}$ solution $(9 \mathrm{~mL})$ from 100 ppm to $<1$ ppm in 60 min (Fig. 2c). In addition, the UV-vis spectra and the optical images of the solution clearly show the efficient removal of $\mathrm{Na}_{2} \mathrm{PdCl}_{4}$ in the solution by the use of IPOF-Cl (Fig. 2d).

The hierarchical porous structure of IPOF-Cl and its high loading capacity of $\left[\mathrm{PdCl}_{4}\right]^{2-}$ further inspired us to investigate
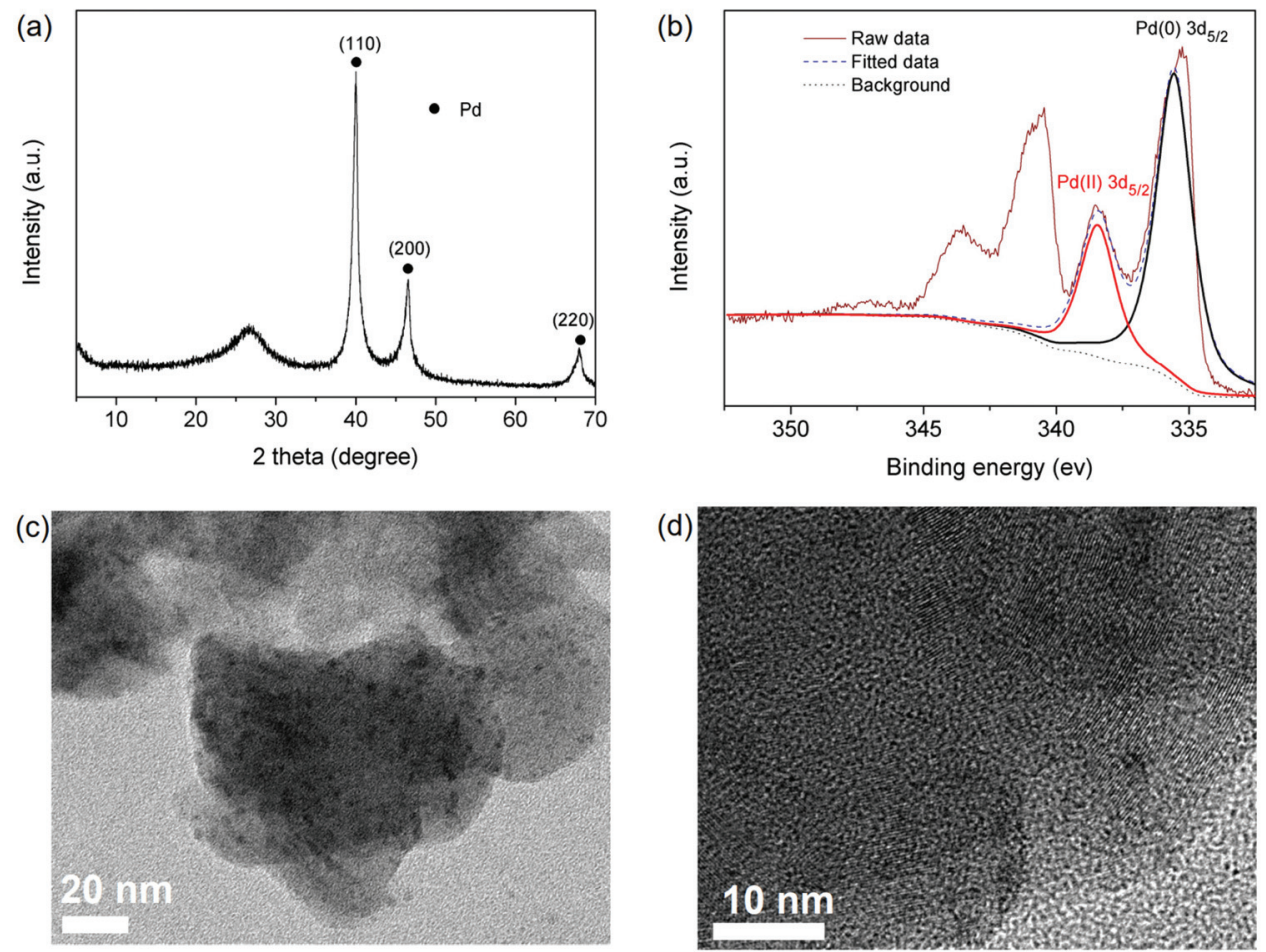

(d)


Fig. 3 (a) Powder X-ray diffraction pattern of IPOF-Pd(0); (b) high-resolution Pd 3d X-ray photoelectron spectrum of IPOF-Pd(0) and its deconvoluted parts; (c) transmittance electron microscopy (TEM) and (d) high-resolution TEM image of IPOF-Pd(0); (e) $\mathrm{N}_{2}$ sorption isotherms of IPOF-Pd(0) recorded at $77 \mathrm{~K}$; (f) pore size distribution of IPOF-Pd(0) calculated from the adsorption isotherm using density functional theory model. 
the potential of IPOF-Cl in heterogeneous catalysis. After capturing $\left[\mathrm{PdCl}_{4}\right]^{2-}$ from the aqueous solution, the solid was collected by centrifugation and then thoroughly washed by water. The obtained complex of IPOF-PdCl $\mathrm{Cl}_{4}$ was redispersed in water, followed by adding $\mathrm{NaBH}_{4}$ to reduce the $\mathrm{Pd}$ (II) species into $\operatorname{Pd}(0)$ nanoparticles that gave IPOF-Pd(0). The composition of IPOF-Pd(0) was examined by XRD analysis. The intensive diffraction peaks at $2 \theta=\sim 40.1,46.5$ and $68.0^{\circ}$ can be attributed to the 110,200 , and 220 reflections of $\operatorname{Pd}(0)$, respectively. The broad diffraction peak at $2 \theta=\sim 26.8^{\circ}$ suggests that the crystalline structure of the IPOF substrate mainly remained intact (Fig. 3a). In addition, no significant change is observed in the infrared spectra (Fig. S6 and S7†). These results demonstrate the high chemical and structural stability of the IPOF. Such high stability for ketoenamine-linked porous organic materials has also been observed in previous studies. ${ }^{41,51,52}$ The highresolution X-ray photoelectron spectroscopy (XPS) spectrum of IPOF-Pd(0) shows two sets of peaks: 338.48 and $335.25 \mathrm{eV}$ in the $\mathrm{Pd} 3 \mathrm{~d}_{5 / 2}$ region and 343.6 and $340.5 \mathrm{eV}$ in the $\mathrm{Pd} 3 \mathrm{~d}_{3 / 2}$ region, indicating the existence of both $\operatorname{Pd}(\mathrm{II})$ and $\operatorname{Pd}(0)$ in the composite (Fig. 3b and S8\%). The deconvolution analysis of the spectrum suggests that it contains $74 \mathrm{wt} \%$ of $\operatorname{Pd}(0)$ and 26 wt\% of Pd(II) species, respectively. The surface Pd content in the composite is calculated to be $31.4 \mathrm{wt} \%$ from the XPS analysis, which is slightly higher than the bulk Pd content (25.4 wt\%) derived from the thermogravimetric analysis of the composite in an air atmosphere (Fig. S9†). Transmission electron microscopy (TEM) images reveal the formation of ultrafine $\mathrm{Pd}$ nanoparticles with a narrow size distribution of $\sim 2-5 \mathrm{~nm}$ in the nanocomposites (Fig. 3c and d). The nanoparticles are uniformly dispersed in the POF substrate and no significant aggregation of the nanoparticles is observed. It appears that the templating effect of IPOF with ordered porous structure plays a key role in the formation of such narrowly distributed ultrafine Pd nanoparticles. ${ }^{52}$ In addition, the interactions between the Pd nanoparticles and the amine groups in the organic framework could also assist the stabilization of the nanoparticles. ${ }^{53,54}$ As expected, the surface area of the composites is reduced to $27 \mathrm{~m}^{2} \mathrm{~g}^{-1}$. Importantly, the pore size distribution analysis of the $\mathrm{N}_{2}$ adsorption isotherm confirms that the hierarchical porous structure of the IPOF substrate remained after loading the Pd nanoparticles (Fig. 3e-f).

The catalytic activity of the IPOF-Pd(0) was evaluated in Suzuki coupling reactions of aryl halides and arylboronic acids in the presence of inorganic base. One of the advantages of the Suzuki coupling reaction is that the reaction can be conducted in various solvents including alcohol and water. Obviously, the high solubility of the arylboronic acid and the inorganic base in water could greatly promote the coupling reaction. More importantly, the use of water as the solvent provides a green and sustainable route for the organic synthesis. However, porous organic materials usually suffer from hydrolytic instability and/or hydrophobic nature preventing their applications in aqueous environments. ${ }^{55,56}$ Remarkably, the covalent nature and the ionic structure of the IPOF substrate endow high water stability and hydrophilicity of the catalyst, respectively, which greatly facilitate its catalytic application in aqueous solution. Therefore, we applied the catalytic reactions

Table 1 Scope of the Suzuki coupling reactions catalyzed by IPOF-Pd(0)

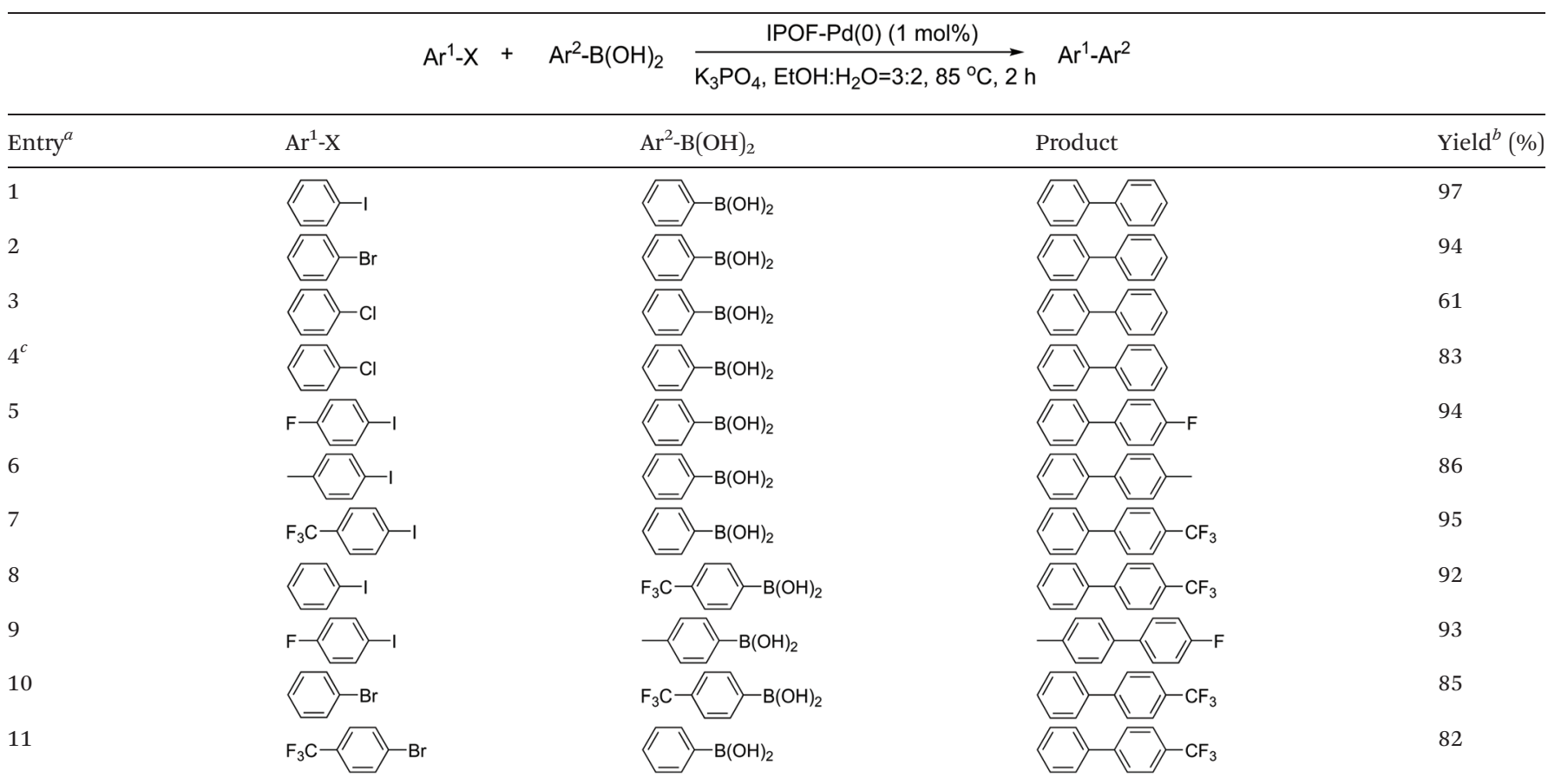

${ }^{a}$ Reaction conditions: IPOF-Pd(0) ( 1 mol\%), aryl halide ( $2.0 \mathrm{mmol}, 1.0$ equiv.), aryl boronic acid $(2.4 \mathrm{mmol}, 1.2 \mathrm{equiv}), \mathrm{K}_{3} \mathrm{PO}_{4}(6.0 \mathrm{mmol}, 3.0$ equiv.), $\mathrm{H}_{2} \mathrm{O}(2.0 \mathrm{~mL}) / \mathrm{EtOH}(3 \mathrm{~mL}), 85^{\circ} \mathrm{C}, 2 \mathrm{~h} .{ }^{b}$ Yield of purified product after silica chromatography. ${ }^{c} \mathrm{IPOF}-\mathrm{Pd}(0)(2 \mathrm{~mol} \%), 6 \mathrm{~h}$. 
in a mixed solvent of water/ethanol $(\mathrm{v}: \mathrm{v}=2: 3)$. As expected, the catalyst showed high catalytic activity for a range of Suzuki coupling reactions (Table 1 ). The coupling reaction between iodobenzene and phenylboronic acid catalyzed by IPOF-Pd(0) ( $1 \mathrm{~mol} \%$ ) gave a high yield of $97 \%$ in $2 \mathrm{~h}$ (entry 1). The use of bromobenzene resulted in a slightly lower yield of $93 \%$ under the same condition (entry 2). Compared to iodobenzene and bromobenzene, chlorobenzene is an ideal starting material for various organic reactions because of its low cost. However, the low reactivity of chlorobenzene usually results in low yields largely limiting its practical uses in coupling reactions. ${ }^{57}$ Noteworthy, IPOF-Pd(0) showed high catalytic activity in the coupling reaction between phenylboronic acid and chlorobenzene. By increasing the catalyst amount to $2 \mathrm{~mol} \%$ and prolonging the reaction time to $6 \mathrm{~h}$, a relatively high yield of $83 \%$ can be achieved (entry 4 ). We also evaluated the scope of the reaction by varying the substituent group of the aryl halides and arylboronic acids. Having electron-withdrawing groups $\left(-\mathrm{CF}_{3},-\mathrm{F}\right)$ or electron-donating groups $\left(-\mathrm{CH}_{3}\right)$ on the organic substrates did not significantly affect the efficiency of the catalyst, which gave high yields of $82-95 \%$ (entries 5-11). A hot filtration experiment was also conducted and we found that no further conversion of the raw materials to the products was observed once the catalyst had been removed. This result suggested that no significant Pd leaching from the IPOF-Pd(0) occurred during the catalysis process due to the high physiochemical stability of the catalyst. In addition, the catalyst showed good recyclability and it can be recycled and used at least 5 times without significant loss of the catalytic activity (Fig. S10†). More importantly, the catalyst showed good chemical and structural stability during the catalytic conversions (Fig. S11 $\dagger$ ). The excellent catalytic performance of the IPOF-Pd(0) in Suzuki coupling reactions can be attributed to the synergetic results of (i) the uniform distribution of ultrafine Pd nanoparticles endowing high catalytic activity of the catalyst; (ii) the hierarchical porous structure of the IPOF substrate allowing for fast mass transport during the catalytic transformations; and (iii) the ionic structure and the resulted good water-dispersibility of the IPOF substrate increasing the compatibility between the starting materials and the catalyst.

\section{Conclusions}

An ionic POF (IPOF-Cl) constructed by guanidinium and ketoenamine linkages has been studied for scavenging and heterogeneous catalysis applications. Owing to its ionic and hierarchical porous structure, IPOF-Cl showed high ion exchange capacity and excellent scavenging ability towards $\left[\mathrm{PdCl}_{4}\right]^{2-}$ in aqueous solutions. In addition, we have developed a new heterogeneous catalyst by reducing the captured $\left[\mathrm{PdCl}_{4}\right]^{2-}$ into Pd nanoparticles. Due to the synergetic effects of uniform distribution of Pd nanoparticles, high physiochemical stability, ionic structure, and hierarchical porous nature of the catalyst, the obtained nanocomposite of IPOF-Pd(0) demonstrated high catalytic activity and good recyclability in a series of Suzuki coupling reactions. We anticipate that the IPOF and its derived materials can be used in recovering precious metal ions, removing heavy metal pollutants, scavenging trace amount of metal ions, and immobilizing homogeneous catalysts that may find important practical applications in mining, water treatment, synthesis and handling of pharmaceuticals, industrial catalysis, and organic synthesis. Future studies may focus on the synthesis and functionalization of novel ionic porous organic materials for gas adsorption and separation, molecular sieving, and ion conduction applications.

\section{Conflicts of interest}

There are no conflicts to declare.

\section{Acknowledgements}

This work was supported by Young Wanjiang Scholar Program and Åforsk research grant (19-493).

\section{References}

1 T. Q. Ma, E. A. Kapustin, S. X. Yin, L. Liang, Z. Y. Zhou, J. Niu, L. H. Li, Y. Y. Wang, J. Su, J. Li, X. G. Wang, W. D. Wang, W. Wang, J. L. Sun and O. M. Yaghi, Science, 2018, 361, 48-52.

2 S.-Y. Ding and W. Wang, Chem. Soc. Rev., 2013, 42, 548568.

3 Y. Li, W. Chen, G. Xing, D. Jiang and L. Chen, Chem. Soc. Rev., 2020, 49, 2852-2868.

4 X. Zou, H. Ren and G. Zhu, Chem. Commun., 2013, 49, 3925-3936.

5 T. Liu and G. Liu, Nat. Commun., 2020, 11, 4984.

6 R. Dawson, A. I. Cooper and D. J. Adams, Prog. Polym. Sci., 2012, 37, 530-563.

7 C. Xu and N. Hedin, Mater. Today, 2014, 17, 397-403.

8 S. Kandambeth, B. P. Biswal, H. D. Chaudhari, K. C. Rout, H. S. Kunjattu, S. Mitra, S. Karak, A. Das, R. Mukherjee, U. K. Kharul and R. Banerjee, Adv. Mater., 2016, 29, 1603945.

9 E. Jin, M. Asada, Q. Xu, S. Dalapati, M. A. Addicoat, M. A. Brady, H. Xu, T. Nakamura, T. Heine, Q. Chen and D. Jiang, Science, 2017, 357, 673.

10 Q. Fang, J. Wang, S. Gu, R. B. Kaspar, Z. Zhuang, J. Zheng, H. Guo, S. Qiu and Y. Yan, J. Am. Chem. Soc., 2015, 137, 8352-8355.

11 A. Acharjya, P. Pachfule, J. Roeser, F.-J. Schmitt and A. Thomas, Angew. Chem., Int. Ed., 2019, 58, 1486514870 .

12 D. D. Medina, V. Werner, F. Auras, R. Tautz, M. Dogru, J. Schuster, S. Linke, M. Döblinger, J. Feldmann, P. Knochel and T. Bein, ACS Nano, 2014, 8, 4042-4052.

13 H. Ding, A. Mal and C. Wang, Mater. Chem. Front., 2020, 4, 113-127. 
14 S.-Y. Ding, J. Gao, Q. Wang, Y. Zhang, W.-G. Song, C.-Y. Su and W. Wang, J. Am. Chem. Soc., 2011, 133, 19816-19822.

15 Y.-N. Gong, W. Zhong, Y. Li, Y. Qiu, L. Zheng, J. Jiang and H.-L. Jiang, J. Am. Chem. Soc., 2020, 142, 16723-16731.

16 Y. Qian, D. Li, Y. Han and H.-L. Jiang, J. Am. Chem. Soc., 2020, 142, 20763-20771.

17 H. Yang, L. Yang, H. Wang, Z. Xu, Y. Zhao, Y. Luo, N. Nasir, Y. Song, H. Wu, F. Pan and Z. Jiang, Nat. Commun., 2019, 10, 2101.

18 T. Banerjee, K. Gottschling, G. Savasci, C. Ochsenfeld and B. V. Lotsch, ACS Energy Lett., 2018, 3, 400-409.

19 C. R. DeBlase, K. E. Silberstein, T.-T. Truong, H. D. Abruña and W. R. Dichtel, J. Am. Chem. Soc., 2013, 135, 16821-16824.

20 X. Kong, S. Zhou, M. Strømme and C. Xu, Carbon, 2021, 171, 248-256.

21 X. Zhao, P. Pachfule, S. Li, T. Langenhahn, M. Ye, C. Schlesiger, S. Praetz, J. Schmidt and A. Thomas, J. Am. Chem. Soc., 2019, 141, 6623-6630.

22 J. Roeser, D. Prill, M. J. Bojdys, P. Fayon, A. Trewin, A. N. Fitch, M. U. Schmidt and A. Thomas, Nat. Chem., 2017, 9, 977.

23 O. Yahiaoui, A. N. Fitch, F. Hoffmann, M. Fröba, A. Thomas and J. Roeser, J. Am. Chem. Soc., 2018, 140, 5330-5333.

24 S. Mitra, S. Kandambeth, B. P. Biswal, A. M. Khayum, C. K. Choudhury, M. Mehta, G. Kaur, S. Banerjee, A. Prabhune, S. Verma, S. Roy, U. K. Kharul and R. Banerjee, J. Am. Chem. Soc., 2016, 138, 2823-2828.

25 Z. Li, H. Li, X. Guan, J. Tang, Y. Yusran, Z. Li, M. Xue, Q. Fang, Y. Yan, V. Valtchev and S. Qiu, J. Am. Chem. Soc., 2017, 139, 17771-17774.

26 N. Huang, P. Wang, M. A. Addicoat, T. Heine and D. Jiang, Angew. Chem., Int. Ed., 2017, 56, 4982-4986.

27 C. Xu, G. Yu, J. Yuan, M. Strømme and N. Hedin, Mater. Today Adv., 2020, 6, 100052.

28 H. Ma, B. Liu, B. Li, L. Zhang, Y.-G. Li, H.-Q. Tan, H.-Y. Zang and G. Zhu, J. Am. Chem. Soc., 2016, 138, 58975903.

29 O. Buyukcakir, S. H. Je, S. N. Talapaneni, D. Kim and A. Coskun, ACS Appl. Mater. Interfaces, 2017, 9, 7209-7216.

30 S. Jansone-Popova, A. Moinel, J. A. Schott, S. M. Mahurin, I. Popovs, G. M. Veith and B. A. Moyer, Environ. Sci. Technol., 2019, 53, 878-883.

31 H.-J. Da, C.-X. Yang and X.-P. Yan, Environ. Sci. Technol., 2019, 53, 5212-5220.

32 K. M. Gupta, K. Zhang and J. Jiang, Ind. Eng. Chem. Res., 2018, 57, 6477-6482.

33 X.-F. Wu, P. Anbarasan, H. Neumann and M. Beller, Angew. Chem., Int. Ed., 2010, 49, 9047-9050.

34 H. Ren, C. A. Strulson, G. Humphrey, R. Xiang, G. Li, D. R. Gauthier and K. M. Maloney, Green Chem., 2017, 19, 4002-4006.
35 S. E. Hankari, A. E. Kadib, A. Finiels, A. Bouhaouss, J. J. E. Moreau, C. M. Crudden, D. Brunel and P. Hesemann, Chem. - Eur. J., 2011, 17, 8984-8994.

36 C. Xu, S. Afewerki, C.-W. Tai, A. Córdova and N. Hedin, ChemistrySelect, 2016, 1, 5801-5804.

37 C. Xu, L. Deiana, S. Afewerki, C. Incerti-Pradillos, O. Córdova, P. Guo, A. Córdova and N. Hedin, Adv. Synth. Catal., 2015, 357, 2150-2156.

38 P. Zhang, Z. Weng, J. Guo and C. Wang, Chem. Mater., 2011, 23, 5243-5249.

39 A. Modak, J. Mondal, M. Sasidharan and A. Bhaumik, Green Chem., 2011, 13, 1317-1331.

40 A. Modak, M. Pramanik, S. Inagaki and A. Bhaumik, J. Mater. Chem. A, 2014, 2, 11642-11650.

41 K. Cui, W. Zhong, L. Li, Z. Zhuang, L. Li, J. Bi and Y. Yu, Small, 2019, 15, 1804419.

42 C. Xu, Z. Bacsik and N. Hedin, J. Mater. Chem. A, 2015, 3, 16229-16234.

43 C. Xu and N. Hedin, Microporous Mesoporous Mater., 2016, 222, 80-86.

44 P. Pandey, A. P. Katsoulidis, I. Eryazici, Y. Wu, M. G. Kanatzidis and S. T. Nguyen, Chem. Mater., 2010, 22, 4974-4979.

45 S.-T. Yang, J. Kim and W.-S. Ahn, Microporous Mesoporous Mater., 2010, 135, 90-94.

46 Y. Su, Y. Wang, X. Li, X. Li and R. Wang, ACS Appl. Mater. Interfaces, 2016, 8, 18904-18911.

47 X. Zhao, X. Bu, T. Wu, S.-T. Zheng, L. Wang and P. Feng, Nat. Commun., 2013, 4, 2344.

48 A. Köllhofer and H. Plenio, Chem. - Eur. J., 2003, 9, 14161425.

49 A. Köllhofer and H. Plenio, Adv. Synth. Catal., 2005, 347, 1295-1300.

50 Y. S. Ho and G. McKay, Process Saf. Environ. Prot., 1998, 76, 332-340.

51 Z. D. Ding, Y. X. Wang, S. F. Xi, Y. Li, Z. Li, X. Ren and Z. G. Gu, Chem. - Eur. J., 2016, 22, 17029-17036.

52 S. Lu, Y. Hu, S. Wan, R. McCaffrey, Y. Jin, H. Gu and W. Zhang, J. Am. Chem. Soc., 2017, 139, 17082-17088.

53 D. Chen, W. Yang, L. Jiao, L. Li, S.-H. Yu and H.-L. Jiang, Adv. Mater., 2020, 32, 2000041.

54 Q. Yang, Q. Xu and H.-L. Jiang, Chem. Soc. Rev., 2017, 46, 4774-4808.

55 L. M. Lanni, R. W. Tilford, M. Bharathy and J. J. Lavigne, J. Am. Chem. Soc., 2011, 133, 13975-13983.

56 A. Li, H.-X. Sun, D.-Z. Tan, W.-J. Fan, S.-H. Wen, X.-J. Qing, G.-X. Li, S.-Y. Li and W.-Q. Deng, Energy Environ. Sci., 2011, 4, 2062-2065.

57 N. Candu, A. Dhakshinamoorthy, N. Apostol, C. Teodorescu, A. Corma, H. Garcia and V. I. Parvulescu, J. Catal., 2017, 352, 59-66. 